\title{
DINÂMICA DA PAISAGEM DO PLANALTO DO RIO CANOAS (SC) NO QUATERNÁRIO TARDIO COM BASE EM REGISTROS PEDOESTRATIGRÁFICOS DE PALEOCABECEIRA DE DRENAGEM
}

\author{
Dayane Pagotto ${ }^{1}$ \\ Julio Cesar Paisani² \\ Michael Vinicius de Sordi ${ }^{3}$
}

Resumo: O estudo da dinâmica quaternária das paisagens do sul do Brasil tem avançado, porém lacunas na escala mesolocal permanecem. A aplicação de descrições pedoestratigráficas, análise granulométrica, determinação de isótopos estáveis do carbono $\left(\mathrm{g}^{13} \mathrm{C}\right)$, análise micromorfológica e o estabelecimento da geocronologia do registro estratigráfico permitiram estabelecer a morfodinâmica de paleocabeceira de drenagem no Planalto do rio Canoas durante o Quaternário Tardio. Essa unidade geomórfica apresenta, em sua maioria, registros pedoestratigráficos cronocorrelatos com outros identificados nas superfícies de cimeiras de Palmas/Caçador (PR-SC) e Vacaria (RS), sugerindo que sua dinâmica ambiental esteve em fases com condições paleoambientais de cunho regional detectadas do Último Interestadial ao Holoceno Superior.

Palavras-Chave: Paleossolo. Colúvio. Paleovoçoroca. Pedoestratigrafia. Paleoambientes.

\section{LANDSCAPE DYNAMICS WITHIN CANOAS RIVER PLATEAU (SC) DURING THE LATE QUATERNARY BASED ON PEDOESTRATIGRAPHIC REGISTERS OF A PALEOVALLEY HEAD}

Abstract: The study of Southern Brazil landscapes quaternary dynamics has progressed, although gaps on the local scale remains. The application of pedostratigraphic descriptions, grain size, stable isotopes of carbon $\left(\rho^{13} C\right)$, micromorphological analysis and the stratigraphic data geochronology determination allowed to define the morphodynamics of a paleovalley head within Canoas river Plateau during the Late Quaternary. Such geomorphic unit presents, mainly, pedostratigraphic records consistent with other records identified on the summit surfaces of Palmas/Caçador (PR-SC) and Vacaria (RS), suggesting that its environmental dynamics was consonant with regional paleoenvironmental conditions detected from the Last Interestedial to the Late Holocene.

Keywords: Paleosoil. Colluvium. Paleogully. Pedostratigraphy. Paleoenvironments.

\footnotetext{
1 Universidade Estadual do Oeste do Paraná, Campus Francisco Beltrão, Departamento de Geografia, Francisco Beltrão, Paraná, Brasil, dayane_pagotto@hotmail.com, https://orcid.org/0000-0003-01909526

2 Universidade Estadual do Oeste do Paraná, Campus Francisco Beltrão, Departamento de Geografia, Francisco Beltrão, Paraná, Brasil, juliopaisani@hotmail.com, https://orcid.org/0000-00028911-6477

${ }^{3}$ Universidade Estadual do Oeste do Paraná, Campus Francisco Beltrão, Departamento de Geografia, Francisco Beltrão, Paraná, Brasil, michael.sordi@gmail.com, http://orcid.org/0000-00018639-7704
} 


\section{DINÁMICA DEL PAISAJE DEL PLANALTO DEL RIO CANOAS/SC EN EL CUATENÁRIO TARDIO CON BASE EN LOS REGISTROS PEDOESTRATIGRÁFICOS DE PEQUEÑA CUENCA FÓSIL}

Resumen: El estudio de la dinámica cuartenária de los paisajes del sur de Brasil han avanzado, sin embargo, hay lagunas y éstas permanecen en la escala meso local. La aplicación de las descripciones pedoestratifigráficas, análisis granulométricos, determinación de isotopos estables del carbono (Q13C), análisis micromorfológica y el establecimiento de la geocronología del registro estratigráfico, han permitido establecer la morfodinámica de pequeña cuenca fósil en el Altiplano del rio Canoas durante el Cuaternario Tardío. Esa unidad geomorfológica presenta en su mayoría pedoestratigraficos cronocorrelactos con otros identificados en las superficies de las cumbres de Palmas (PR)-Caçador (SC) y Vacaria (RS), señalando que su dinámica ambiental estuvo en fases con las condiciones de cuño regional detectadas del Último Interestadio al Holoceno Superior.

Palabras clave: Paleosuelo. Coluvión. Paleoquebrada. Pedoestratigrafia. Paleoambíentes.

\section{Introdução}

A dinâmica natural das áreas planálticas da região sul do Brasil é tema que tem conduzido pesquisas de cunho, por exemplo, morfoestrutural (Sordi et al., 2015;2017;2018), morfotectônico (Jacques et al.,2014; 2015; Nummer et al.,2014), morfoclimático (Camargo Filho, 1997; Melo et al., 2003a; b; Passos e Camargo Filho, 2015), paleoclimático (Melo et al., 2003a;b; Behling et al., 2004; Moro et al., 2004; Oliveira et al., 2008; Luz et al., 2019), paleopedológico (Calegari, 2008; Paisani et al., 2013; 2014; Camargo Filho et al., 2016) e morfodinâmico (PEREIRA, 2017; BIFFI, 2019). Nesse último caso, bacias de baixa ordem hierárquica têm assumido papel de destaque na identificação das respostas dos componentes das paisagens (relevo, sedimentos, solos e vegetação) diante das mudanças ambientais impulsionadas pelas variações climáticas do Quaternário Tardio (PAISANI et al., 2016; 2019a).

Embora notem-se avanços no conhecimento da dinâmica das áreas planálticas da região sul no país, devido a significativa variabilidade paisagística e extensão regional, ainda há uma lacuna quanto a estudos em escala mesolocal que mostrem as respostas das paisagens a mudanças climáticas globais (PAISANI et al., 2019b). Nesse contexto, as bacias de baixa ordem hierárquica $\left(<4^{\underline{a}}\right.$ ordem na classificação de Strahler, 1957), assumem papel importante ao representar a conexão dinâmica entre os processos de encostas e do ambiente fluvial (OLIVEIRA, 1996; PAISANI et al., 2016). O desafio em se estudar áreas em escala mesolocal é justamente distinguir fenômenos de cunho regional de outros locais. Acredita-se que 
descrições sistemáticas de seções pedoestratigráficas em bacias de baixa ordem em diferentes compartimentos ao longo das áreas planálticas da região sul possam contribuir para construir um cenário regional dos efeitos das mudanças climáticas globais nas paisagens dessa região.

Nesse sentido, buscou-se expandir as pesquisas de dinâmica paleoambiental quaternária tardia para o Planalto do rio Canoas-SC (SORDI et al., 2016). Para isso, o presente estudo se baseou na análise de registros estratigráficos de paleocabeceira de drenagem e descrições pedoestratigráficas a partir de informações de campo, análises micromorfológicas e isotópica estável do carbono, bem como a determinação geocronológica dos principais fatos estratigráficos.

\section{Área de Estudo}

A paleocabeceira de drenagem estudada se individualiza diante de seção estratigráfica transversal ao seu hollow que está exposta, com cerca de $360 \mathrm{~cm}$ de extensão, em corte de estrada rural. Ela se encontra no sistema hidrográfico da bacia do rio Canoas, entre as coordenadas $27^{\circ} 07^{\prime} 23,6^{\prime \prime} \mathrm{S} ; 50^{\circ} 24^{\prime} 52,4^{\prime \prime}$ W, estado de Santa Catarina (Figura 1A). O nome desse rio é usado como toponímia para designar o relevo local de Planalto do rio Canoas (SORDI et al. 2016). Tal planalto se insere na unidade morfoestrutural Planalto Basáltico de Santa Catarina (PelusoJúnior, 1986), que juntamente com demais unidades de relevo similares da Bacia do Paraná se integram nos Planaltos Subtropicais com Araucárias (PAISANI et al., 2019a). O Planalto do rio Canoas contempla altitudes entre $720 \mathrm{~m}$ no vale do rio Canoas a $1.312 \mathrm{~m}$ na Serra do Espigão (Figura 1b), com declividade média de 11\% e dissecação baixa nas áreas de topo (SORDI et al., 2016).

Esse planalto é mantido por rochas vulcânicas mesozoicas (Grupo Serra Geral) e sedimentares (Grupo São Bento) da Bacia Sedimentar do Paraná (Figura 1a). Localmente, devido a forte dissecação dos tributários do rio Canoas, em particular o rio Correntes (Figura 1b), os topos das colinas são mantidos por basalto e as encostas por arenito da Formação Botucatu, como é o caso do local onde se encontra a paleocabeceira de drenagem estudada. 
Figura 1 - Localização da área de estudo em relação à Bacia Sedimentar do Paraná $(A)$; e em relação ao Planalto de Canoas $(B)$. Perfil geológico-geomorfológico da rampa de colúvios $(\mathrm{C})$

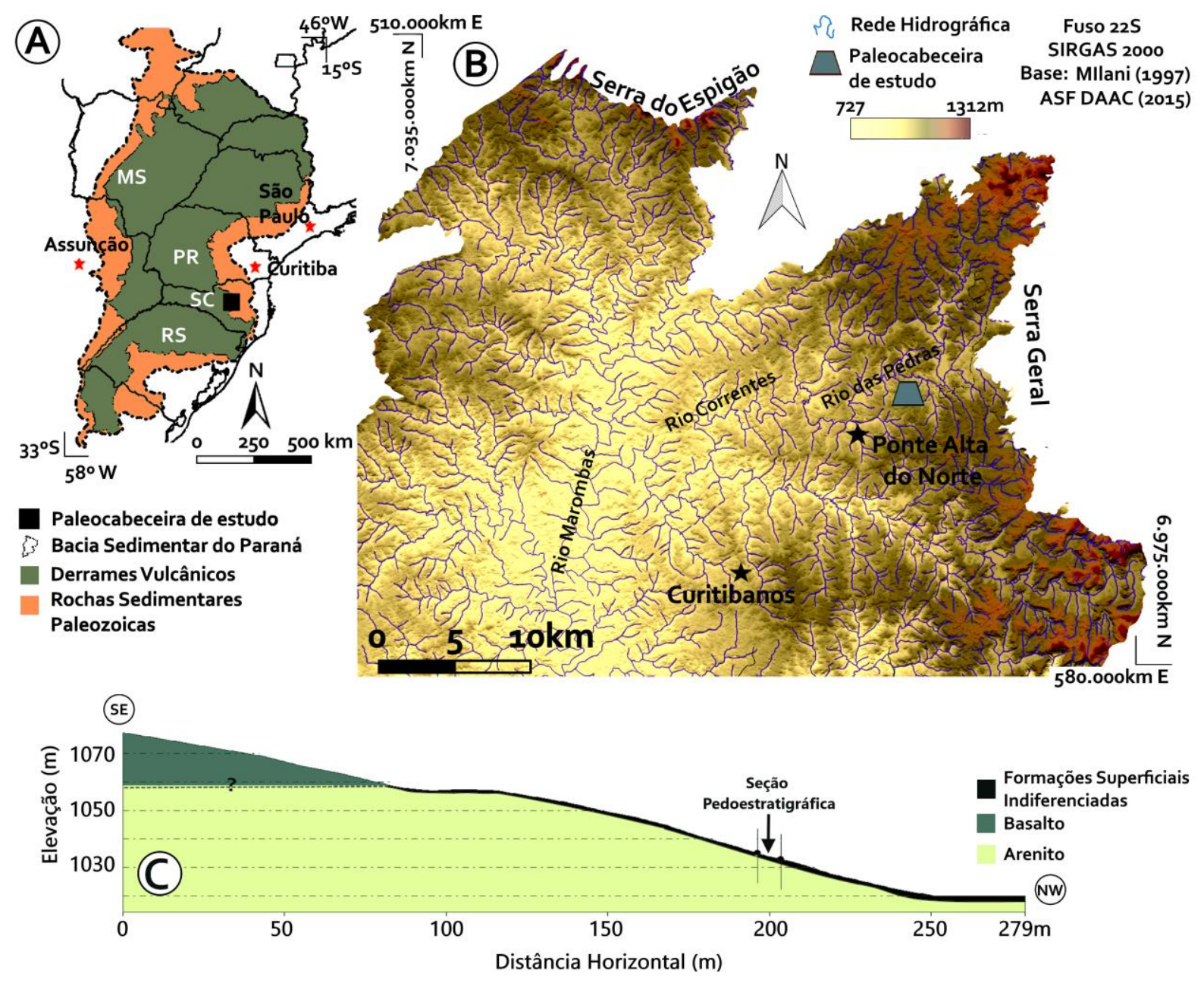

Tais características geológico-geomorfológicas não permitem 0 desenvolvimento de perfis de alteração muito espessos nas áreas de topo, o que implica em relevo de forte a moderadamente ondulado. Essas características do relevo influenciam os tipos de solo encontrados na área. Observações em campo sugerem que Nitossolos brunos ocupam áreas de topo de relevo moderadamente ondulado, enquanto Cambissolos e Neossolos litólicos são gerados nos topos fortemente ondulados e nas encostas, ao passo que Gleissolos a Organossolos formam-se em fundos de vales e depressões fechadas.

O regime climático do Planalto do Rio Canoas é Cfb, mesotérmico temperado, na classificação de Köppen (Alvares et al., 2014), com média pluviométrica entre $1.897 \mathrm{~mm} \cdot \mathrm{ano}^{-1}$ e $1.930 \mathrm{~mm} \cdot \mathrm{ano}^{-1}$ bem distribuída e temperatura média anual de $16^{\circ} \mathrm{C}$ e $16,8^{\circ} \mathrm{C}$, nas estações de Campos Novos $\left(27,38^{\circ} \mathrm{S} ; 51,2^{\circ} \mathrm{W}\right)$ e Lages (27,81우 $\left.50,33^{\circ} \mathrm{W}\right)$ (INMET, 2019), respectivamente. A vegetação natural da 
área, fortemente substituída por cultivos, sobretudo Pinus elliotti, pode não representar esse regime climático moderno (Paisani et al., 2019a), pois registra-se área de contato entre Savana (Campos) e Floresta Ombrófila Mista (SANTA CATARINA, 1986).

\section{Materiais e Métodos}

Os materiais da seção estudada foram individualizados levando-se em consideração conjuntamente os critérios lito-, alo- e pedoestratigráficos (HUGHES, 2010). O critério litoestratigráfico se baseou na individualização das camadas com base em características reconhecidas inicialmente em campo, como cor, geometria e textura simplificada conforme Ghibaudo (1992), ao longo de oito janelas de observação. Em seguida, aferiu-se os limites e a individualização das unidades, bem como se subdividiu aquelas que aparentavam serem homogêneas em campo com base em diagrafias granulométricas (PAISANI, 2004), reconhecendo-se tendências verticais granulométricas em intervalos de um $\varphi$ (phi) (Krumbein, 1934), das frações argila a seixo.

Foram coletadas de forma sistemática, a cada $10 \mathrm{~cm}$ de profundidade, um total de dezessete amostras deformadas em uma janela de observação onde ocorrem o conjunto das unidades estratigráficas. As amostras foram tratadas em laboratório utilizando-se peneiramento para a fração grossa e pipetagem para a fração fina, com separação via úmida utilizando peneira de 0,063 mm, conforme Paisani (1998).

Alguns limites entre as unidades são marcados por descontinuidades na pedogênese e erosão. Devido a recorrente incidência da pedogênese, a sequência estratigráfica recebeu nomenclatura final pedoestratigráfica (BIRKELAND, 1999). A descrição pedológica em campo seguiu os procedimentos convencionais, onde reconheceu-se cor (Munsell Soil-Color Chart), estrutura, consistência, entre outros atributos pedológicos (Santos et al., 2005). A classe textural foi determinada plotando-se os percentuais da análise granulométrica no diagrama ternário padrão USDA (SCHAETZL e ANDERSON, 2005). A geometria externa dos materiais da seção estratigráfica foi reproduzida em escala 1:20.

Em sete amostras deformadas dos principais níveis estratigráficos foi inferido o tipo de paleovegetação da área com base na determinação da razão isotópica do carbono $\left(\delta^{13} \mathrm{C}={ }^{13} \mathrm{C} /{ }^{12} \mathrm{C}\right)$ (BENDER, 1971; NEWMAN et al., 1973; 
DEINES, 1980; BOUTTON,1996). O $\delta^{13} \mathrm{C}$ foi determinado por espectrometria de massa no laboratório de Isótopos Estáveis do Centro de Energia Nuclear na Agricultura (CENA, Universidade de São Paulo) e teve por referência o padrão PDB (molusco fóssil Belemnitella americana da Formação Peedee), como demonstra a expressão $\delta^{13} \mathrm{C}(\%)=\left[\left({ }^{13} \mathrm{C} /{ }^{12} \mathrm{C}\right.\right.$ da amostra) $/\left({ }^{13} \mathrm{C} /{ }^{12} \mathrm{C}\right.$ do PDB $\left.\left.{ }^{-1}\right) \cdot 10^{3}\right]$ (BENDER, 1971).

Dos principais níveis pedoestratigráficos quatro amostras indeformadas foram coletadas para análise micromorfológica. A impregnação e laminação das amostras foram realizadas pelo Laboratório de Laminação do Instituto de Geociências da USP. A descrição foi realizada no Laboratório de Microscopia Ótica da Unioeste, Campus de Francisco Beltrão, utilizando-se microscópio trinocular Leica DM 2500 P, câmera Leica EC3 e o software Leica Application Suíte LAS EZ versão 1.4, com base na nomenclatura e critérios descritivos de Stoops (2003).

A cronologia do registro estratigráfico foi estabelecida determinando-se a idade pelos métodos do ${ }^{14} \mathrm{C}$ - para o nível de epipedon enterrado mais profundo - e luminescência opticamente estimulada (LOE) para determinar a cronologia dos três principais níveis coluviais. A idade da amostra submetida ao método ${ }^{14} \mathrm{C}$ foi determinada pelo Laboratório Beta Analytic Inc. (USA), utilizando-se a técnica de AMS (Accelerator Mass Spectrometry). A idade ${ }^{14} \mathrm{C}$ se refere à data em que a amostra parou de trocar carbono com sua fonte, medida a partir da quantidade de ${ }^{14} \mathrm{C}$ residual relativa a um padrão moderno (DUTTA, 2016). Já as idades pelo método de LOE foram estabelecidas pelo Laboratório de Datação, Comércio e Prestação de Serviço Ltda (São Paulo, Brasil), utilizando-se a técnica SAR com quinze alíquotas em grãos de quartzo. A LOE, por sua vez, permite estimar o intervalo de tempo desde que grãos minerais foram expostos pela última vez a luz do dia, utilizando-se de sua resposta à radiação ionizante (RHODES, 2011).

\section{Resultados}

Caracterização morfopedológica dos materiais e geometria externa dos registros pedoestratigráficos

No contexto estratigráfico atual a paleocabeceira de drenagem está soterrada e fossilizada na paisagem, configurando-se como contínuo lateral de uma rampa de colúvio (Figura $2 \mathrm{~A}$ ), cuja morfologia é côncava na média e alta encosta e convexa no topo (Figura 1C, 2A). O registro estratigráfico da paleocabeceira de 
drenagem é constituído de sedimento tecnogênico (nível 1), colúvios com níveis pedogeneizados (níveis 2 a 5) e saprolito de arenito (nível 6) (Quadro 1; Figura 2B,C).

Figura 2 - Contexto geomorfológico da paleocabeceira de drenagem colmatada. (A) Relevo residual com caos de blocos de basalto, rampa de colúvio suavemente convexa e paleocabeceira de drenagem no ápice da convexidade de rampa de colúvio. (B) Seção estratigráfica onde se destacam epipedons enterrados e afloramento de saprolito de arenito hidromórfico. (C) Arquitetura da seção estratigráfica com a identificação de horizontes.
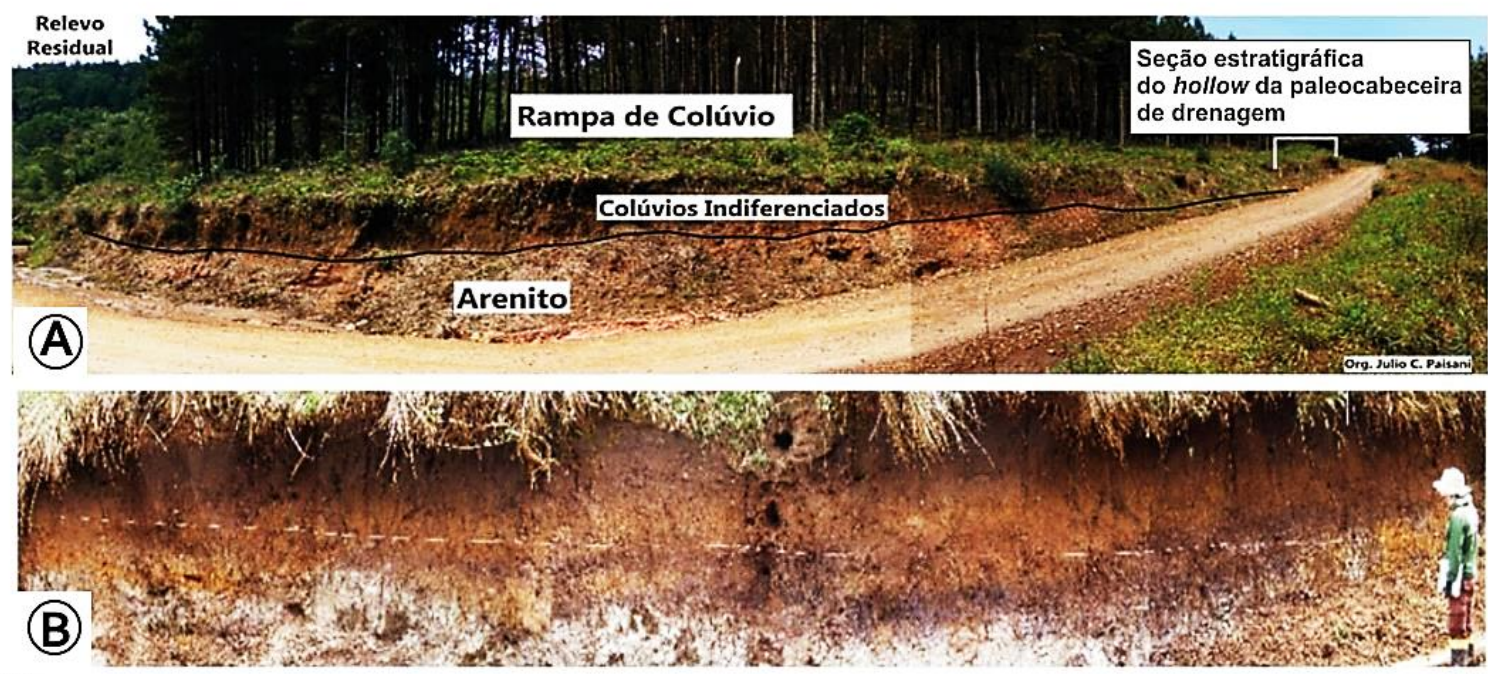

NE

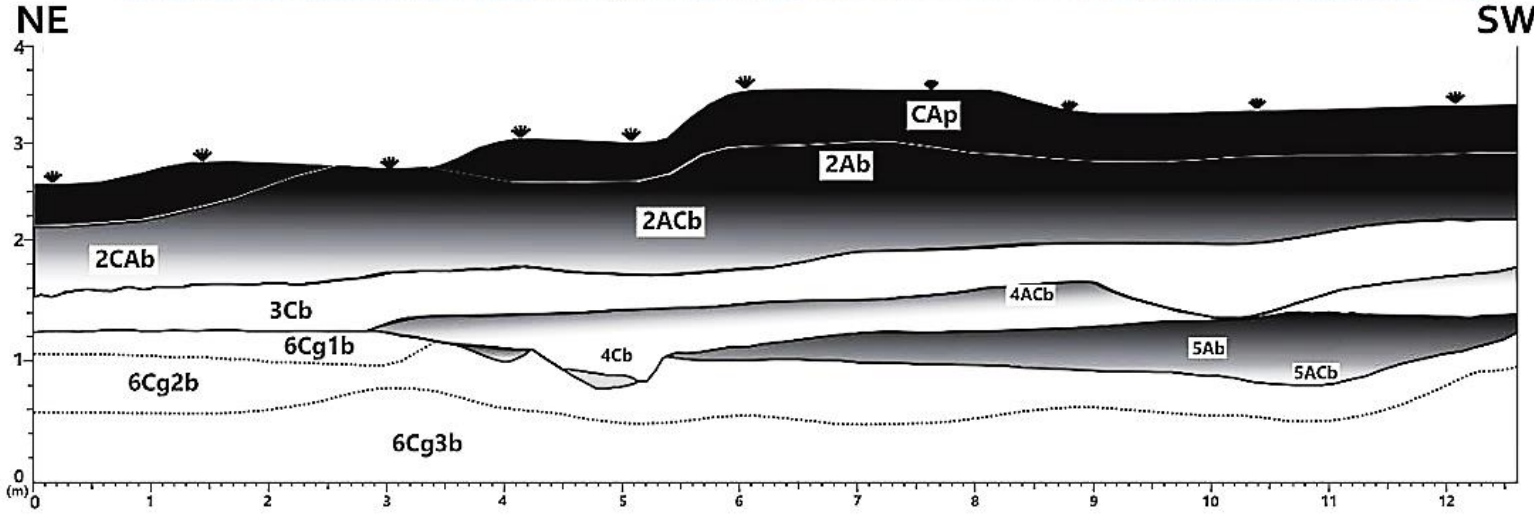

(C)

$\mathrm{Cb}$ Colúvios Indiferenciados $\square$ Epipedon organo-mineral $\quad$ GPedorreliquea Horizonte A

Quadro 1 - Atributos morfopedológicos dos materiais do hollow da paleocabeceira de drenagem.

\begin{tabular}{|c|c|c|c|c|c|c|c|}
\hline \multirow{2}{*}{ Horizonte } & \multirow{2}{*}{$\begin{array}{l}\text { Prof. } \\
\text { (cm) }\end{array}$} & \multirow{2}{*}{ Cor $^{4}$} & \multirow{2}{*}{$\underset{2}{\text { Textura }}$} & \multirow{2}{*}{ Estrutura $^{3}$} & \multicolumn{2}{|c|}{ Consistência } & \multirow{2}{*}{ Outras Características } \\
\hline & & & & & $\mathrm{Seca}^{4}$ & Úmida & \\
\hline CAp & $0-60$ & 10YR $4 / 3$ & $\mathrm{Ra}$ & $\mathrm{M}$ & LD & $\mathrm{Fi}$ & $\begin{array}{l}\text { Blocos de basalto e } \\
\text { arenito; raízes e } \\
\text { pedoturbação }\end{array}$ \\
\hline
\end{tabular}




\begin{tabular}{|c|c|c|c|c|c|c|c|}
\hline $2 \mathrm{Ab}$ & $60-80$ & 10YR $3 / 2$ & $\mathrm{~F}-\mathrm{Fa}$ & $M-G r^{f a}$ & LD & $\mathrm{Fi}$ & Raízes e pedoturbação \\
\hline $2 \mathrm{ACb}$ & $80-110$ & 10YR $3 / 2$ & $\mathrm{~F}$ & $\mathrm{Gr}_{\mathrm{fa}}^{\mathrm{f}}$ & LD & $\mathrm{Fr}$ & - \\
\hline $2 C A b$ & $110-125$ & 10YR 3/2 & $\mathrm{Ra}-\mathrm{Fr}$ & $\mathrm{Bs}^{\mathrm{fa}}$ & LD & $\mathrm{Fr}$ & - \\
\hline $3 \mathrm{Cb}$ & $125-180$ & $\begin{array}{c}\text { 10YR 4/3- } \\
\text { 10YR 4/4 }\end{array}$ & Fr-R & $\mathrm{Bs}^{\mathrm{fa}}$ & LD & $\mathrm{Fr}$ & - \\
\hline $4 \mathrm{ACb}$ & $180-190$ & 10YR 3/2 & $\mathrm{R}$ & $\mathrm{Bs}^{\mathrm{fa}}$ & $\mathrm{MD}$ & $\mathrm{Fi}$ & Pedoturbação \\
\hline $4 \mathrm{Cb}$ & 190-205 & 10YR 4/2 & Fra & Bs-Pm & ED & Mfi & - \\
\hline $5 A b$ & $205-215$ & 10YR $3 / 2$ & $\mathrm{Fr}$ & $B s^{f a-m}$ & MD & $\mathrm{Fi}$ & $\begin{array}{l}\text { Traços de raízes } \\
\text { fasciculadas; } \\
\text { pedoturbação }\end{array}$ \\
\hline $5 \mathrm{ACb}$ & $215-225$ & 10YR 4/3 & Fra-Fa & $B s^{f a-m}$ & MD & $\mathrm{Fi}$ & Pedoturbação \\
\hline $6 \mathrm{Cg} 1 \mathrm{~b}$ & $225-245$ & GLEY1 8/N & Fra-Fa & $M-G^{f a}$ & LD & Mfr & - \\
\hline $6 \mathrm{Cg} 2 \mathrm{~b}$ & 245-305 & $\begin{array}{c}\text { GLEY1 6/10Y - } \\
\text { GLEY1 6/N }\end{array}$ & Fa-Fra & $M-G^{\text {fa }}$ & $\mathrm{Ma}$ & Mfr & - \\
\hline $6 \mathrm{Cg} 3 \mathrm{~b}$ & $305-360$ & $\begin{array}{c}\text { GLEY1 6/N- } \\
\text { GLEY1 7/N - } \\
\text { GLEY1 8/N }\end{array}$ & Af-Fa & $M-G^{\text {fa }}$ & Ma. & Mfr & - \\
\hline
\end{tabular}

Segundo Munsell Color Chart.

2Diagrama triangular da USDA (Schaetzl e Anderson, 2005), Af:areia franca, F:franco, Fa:francoarenosa, Fr:franco-argilosa, Fra:franco-argilo-arenosa, R:argilosa, Ra:argila-arenosa,

${ }^{3}$ Gr: grumosa, Bs: blocos subangulares, M: maciça, P: prismática, fafraca, ${ }^{m}$ moderada, ${ }^{\text {foforte. }}$

${ }^{4} \mathrm{LD}$ :ligeiramente dura, MD:muito dura, ED:extremamente dura, Ma:macia.

${ }^{5} \mathrm{Fi}$.: firme, Fr:friável, Mfi:muito firme, Mfr:muito friável.

O nível pedoestratigráfico 1 possui apenas um horizonte superficial, o CAp, composto por lama cascalhenta organo-mineral (Ghibaudo, 1992) e corresponde a material tecnogênico (PELOGGIA, 1998). Sua gênese está associada a remobilização de parte do terreno pelo cultivo recorrente de Pinus elliottii, haja vista que a encosta se encontra reflorestada (Figura 2A). Já o nível pedoestratigráfico 2 se divide em três horizontes: $2 A b, 2 A C b$ e $2 C A b$, compostos por lama organomineral, com sutis diferenças entre os horizontes, como transições gradacionais, devido a atuação posterior da pedogênese sobre esses materiais (Figura $2 B ; C$ ).

O nível pedoestratigráfico 3 é constituído pelo horizonte $3 \mathrm{Cb}$ cuja principal característica é sua textura, lama arenosa a areia. Seus limites com a unidade sobrejacente só foram determinados a partir da diagrafia granulométrica, pois em campo os horizontes $2 \mathrm{CAb}$ e $3 \mathrm{Cb}$ apresentam transição gradual (PAGOTTO, 2018). A reconstituição da arquitetura do registro estratigráfico revelou que, lateralmente, o horizonte $3 \mathrm{Cb}$ se encontra em contato abrupto com os horizontes do saprolito, bem como preenchendo uma das gerações de incisões erosivas do registro estratigráfico que truncou o nível subjacente (Figura 2B,C). A incisão erosiva é um dos registros mais importantes da paleocabeceira de drenagem, pois sugere que $O$ contato 
abrupto entre os níveis 3 e 4 foi marcado por uma paleosuperfície no hollow da cabeceira de drenagem, implicando em fase de morfogênese marcada pela erosão, antes do estabelecimento do nível 3.

O nível pedoestratigráfico 4 é composto pelos horizontes $4 \mathrm{ACb}$ e $4 \mathrm{Cb}$. horizonte $4 \mathrm{ACb}$ se destaca por se tratar de um paleohorizonte enterrado, constituído de lama organo-mineral com distribuição lateral descontínua para o setor NE da seção estratigráfica (Figura 2B;C). O horizonte 4Cb é constituído por lama arenosa, de origem coluvial que colmatou uma das gerações de incisão erosiva e truncou o nível subjacente (Figura 2B;C). Justamente na base da incisão erosiva ocorre lente de material organo-mineral. Tal estrutura é similar aquelas encontradas colmatando paleovoçorocas na Superfície de Cimeira de Palmas/Caçador (Paisani et al., 2014), e corresponde a pedorrelíquia de epipedon incorporada ao substrato coluvial durante a sua deposição (Figura 2C).

O nível pedoestratigráfico 5 compreende os horizontes $5 \mathrm{Ab}$ e $5 \mathrm{ACb}$, ambos constituídos por lama organo-mineral. Em campo, esse nível pedoestratigráfico se mostra homogêneo em contato gradacional com o saprolito do Arenito Botucatu, subjacente (Figura 2B). Contudo, na análise micromorfológica (item 4.2), percebeuse litorrelíquias de basalto que lhe conferem gênese coluvial. Isso leva a considerar um epipedon enterrado coluvial que, por sua vez, pode ter se espessado cumulativamente pelo aporte de material organo-mineral de sucessivos eventos geogenéticos na encosta circundante ao hollow da paleocabeceira de drenagem (SCHAETZL e ANDERSON, 2005). Essa ideia vai ao encontro do fato do horizonte $5 \mathrm{ACb}$ se encontrar em contato abrupto com o saprolito, que corresponde ao nível 6. Isto é, o nível pedoestratigráfico 5 foi truncado lateralmente e verticalmente pela erosão, em face da incisão linear.

O saprolito deriva do Arenito Botucatu e se mostra hidromórfico com variações na cor e textura que permite subdividi-lo nos horizontes $6 \mathrm{Cg} 1 \mathrm{~b}, 6 \mathrm{Cg} 2 \mathrm{~b}$ e 6Cg3b (Figura 2B,C). Esses horizontes não preservam mais a estrutura original do arenito, correspondendo, atualmente, a saprolito grosso na conceituação de Tardy (1993).

Análise micromorfológica

A análise micromorfológica foi realizada em quatro horizontes, do topo em direção a base da seção estratigráfica: $2 \mathrm{Ab}, 3 \mathrm{Cb}, 4 \mathrm{Cb}$ e na transição entre os 
horizontes 5Ab e 5ACb (Quadro 2). O horizonte 2Ab se caracteriza por distribuição relativa predominante porfírica fechada, fração grossa com quartzo, ilmenita/magnetita, nódulos pedomórficos e litomórficos intrusivos e pedorrelíquias de agregado (Figura 3A). Observam-se poros com preenchimento solto descontínuo e a presença de sutis hiporevestimentos de depleção e de impregnação.

Quadro 2 - Principais atributos micromorfológicos dos horizontes $2 \mathrm{Ab}, 3 \mathrm{Cb}, 4 \mathrm{Cb}$ e transição dos horizontes $5 \mathrm{Ab}$ e $5 \mathrm{ACb}$.

\begin{tabular}{|c|c|c|c|c|c|c|c|c|c|c|}
\hline & \multirow{2}{*}{\multicolumn{2}{|c|}{ Fração Grossa }} & \multirow{2}{*}{\multicolumn{2}{|c|}{ Micromassa }} & \multirow{3}{*}{ DRCe } & \multirow{3}{*}{$\mathrm{GP}^{\mathrm{f}}$} & \multirow{3}{*}{ Poros. ${ }^{g}$} & \multirow{3}{*}{$\begin{array}{l}\text { Pedofeições } \\
\text { Mátricas }^{\text {h }}\end{array}$} & \multirow{3}{*}{$\begin{array}{c}\text { Pedofeiçõe } \\
\text { s } \\
\text { Intrusivas }^{i}\end{array}$} \\
\hline & & & & & & & & & & \\
\hline $\begin{array}{c}\text { Horiz } \\
.\end{array}$ & $\begin{array}{l}\text { Prof. } \\
\text { (cm) }\end{array}$ & Comp. $^{a}$ & Comp. $^{a}$ & Cor $^{c}$ & $\begin{array}{l}\text { Fábrica } \\
\text { Matriz }^{d}\end{array}$ & & & & & \\
\hline $2 A b$ & $75-80$ & $\begin{array}{c}\text { Qz,I/M } \\
\text { Npi,Nli, } \\
\text { Pe }\end{array}$ & $\begin{array}{c}a m f^{1}, \\
a f^{1}, \\
a m^{2}, a^{2} \\
\end{array}$ & bae & $\begin{array}{l}\text { in }^{1} \\
\text { esm }\end{array}$ & $\begin{array}{l}\mathrm{pf}^{1} \\
\mathrm{pfs}^{2}\end{array}$ & pm-pf & $\begin{array}{l}\mathrm{pl}^{3}, \mathrm{v}^{2} \\
\mathrm{c}^{1}, \mathrm{co}^{1}\end{array}$ & ntp, hcd, hci & $\begin{array}{c}\text { ntl, ntp, } \\
\text { nnp, nsl, } \\
\text { pe }\end{array}$ \\
\hline $3 \mathrm{Cb}$ & $\begin{array}{l}150- \\
160\end{array}$ & $\begin{array}{l}\text { Qz, I/M } \\
\text { Npi,Nli, } \\
\text { Li, Pe }\end{array}$ & $\begin{array}{c}a m f^{1}, \\
a f^{1}, \\
a m^{2}, a g^{2}\end{array}$ & bae & $\begin{array}{l}\text { in }^{1} \\
\text { esm }\end{array}$ & $\begin{array}{l}\mathrm{pf}^{1} \\
\mathrm{pfs}^{2}\end{array}$ & pm-pf & $\begin{array}{l}\mathrm{pl}^{3}, \mathrm{a}^{2}, \\
\mathrm{cv}^{1}, \mathrm{c}^{1}\end{array}$ & hcd, ntp & $\begin{array}{c}\text { ntl, ntp, } \\
\text { nnp, li, pe }\end{array}$ \\
\hline $4 \mathrm{Cb}$ & $\begin{array}{l}195- \\
205\end{array}$ & $\begin{array}{c}\text { Qz, I/M, } \\
\text { Al } \\
\text { Npi, Nli, } \\
\text { Li }\end{array}$ & $\begin{array}{c}a m f^{1}, \\
a f^{1}, \\
a m^{2}, a^{2}\end{array}$ & bae & $\begin{array}{l}\text { in }^{1} \\
\text { esm }\end{array}$ & $\begin{array}{l}\mathrm{pf}^{1}, \\
\mathrm{pfs}^{2}\end{array}$ & pm-pf & $\begin{array}{c}\mathrm{pl}^{2}, \mathrm{v}^{2} \\
\mathrm{ca}^{2} \\
\mathrm{c}^{1} \\
\mathrm{co}^{1}\end{array}$ & hcd & $\begin{array}{l}\text { ntl, ntp, li, } \\
\text { ali }\end{array}$ \\
\hline $\begin{array}{c}5 A b- \\
5 A C \\
b\end{array}$ & $\begin{array}{l}215- \\
225\end{array}$ & $\begin{array}{c}\text { Qz, I/M } \\
\text { Npi,Nli, } \\
\text { Li, Pe }\end{array}$ & $\begin{array}{c}a m f^{1}, \\
a f^{1}, \\
a m^{2}, a g^{2}\end{array}$ & be & $\begin{array}{l}\text { in }^{1} \\
\text { esm }\end{array}$ & $\begin{array}{l}\mathrm{pf}^{1} \\
\mathrm{pfs}^{2}\end{array}$ & pm-pf & $\begin{array}{c}\mathrm{pl}^{3}, \\
\mathrm{v}^{3}, \mathrm{ca}^{1}, \\
\mathrm{c}^{1}, \mathrm{co}^{1}\end{array}$ & hcd, hci, cc & $\begin{array}{l}\text { ntl, ntp, li, } \\
\text { pe }\end{array}$ \\
\hline
\end{tabular}

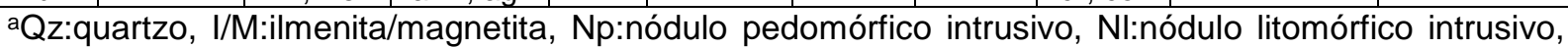
Pe: pedorrelíquia, Li: litorrelíquias, Al :alteromorfo.

${ }^{b}$ amf $=$ areia muito fina, $a f=$ areia fina, $a m=$ areia média, $a g=$ areia grossa. ${ }^{1}$ predominante, ${ }^{2}$ localmente. cMunsell Color Chart, bae: bruno amarelado escuro (10YR 3/4), be:bruno escuro (7.5YR 3/2).

din: indiferenciada, esm: cristalítica estriada/ monoestriada, ${ }^{1}<10 \%,{ }^{2}<40 \%,{ }^{3} \geq 40 \%$.

eDRC: distribuição relativa dos constituintes, pf:porfírica fechada, pfs:porfírica fechada singular.

fGP: grau de pedalidade, pm:pédico com pedalidade moderadamente desenvolvida, pf:pédico com pedalidade fracamente dese nvolvida.

${ }^{9} \mathrm{Co}$ :composto, c:canal, ca: câmara, cv:cavitário, pl:planar, ${ }^{1}<10 \%,{ }^{2}<40 \%, 3 \geq 40 \%$.

hntp: nódulo típico pedomórfico, hcd :hipocutan de depleção, hci:hipocutan de impregnação, cc:cutan de crescimento.

intl= nódulo típico litomórfico, ntp: nódulo típico pedomórfico, nnp:nódulo nucleico pedomórfico, nsi: nódulo septárico intrusivo, li: litorrelíquia, ali:alterorrelíquia de basalto, pe:pedorrelíquia. 
Figura 3 - Micrografia dos horizontes $2 \mathrm{Ab}, 3 \mathrm{Cb}, 4 \mathrm{Cb}$ e transição dos horizontes $5 \mathrm{Ab}$ e $5 \mathrm{ACb}$. Pedorrelíquias de agregado nos horizontes $2 \mathrm{Ab}$ e $3 \mathrm{Cb}-\mathrm{LNP}(\mathrm{A}, \mathrm{B})$. Alterorrelíquia de basalto no horizonte $3 \mathrm{Cb}$ - LNP (C). Litorrelíquia de basalto e geodo no horizonte $4 \mathrm{Cb}-$

LNP (D). Sutis laminações (I, II e III) e pedoturbação (câmara) na transição entre os horizontes $5 \mathrm{Ab} / 5 \mathrm{ACb}$ - LNP (E). Revestimentos de iluviação localmente encontrados entre os horizontes $5 \mathrm{Ab} / 5 \mathrm{ACb}-\mathrm{NC}(\mathrm{F})$.
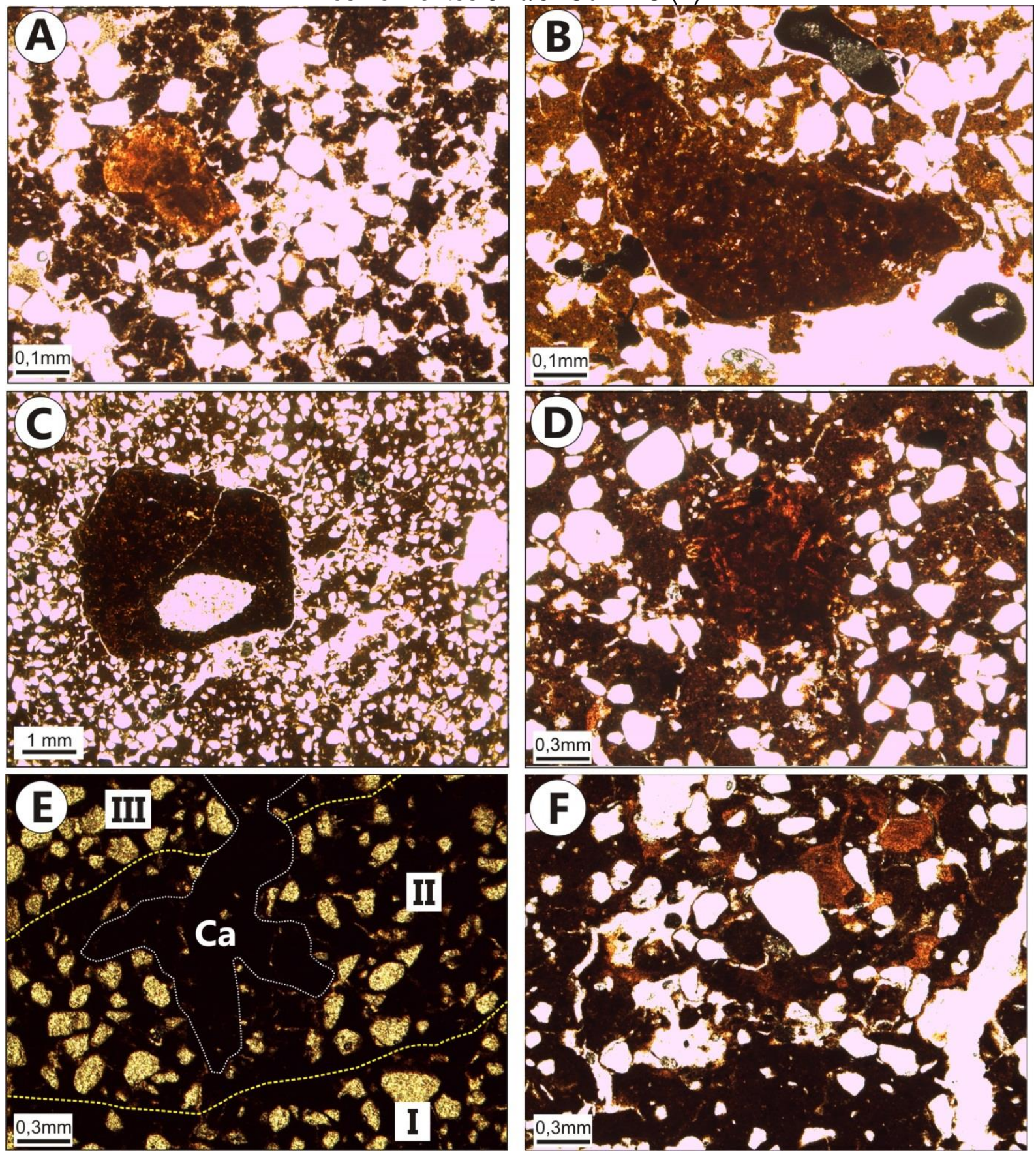

O horizonte $3 \mathrm{Cb}$ exibe distribuição relativa predominante porfírica fechada, com grãos de quartzo, grãos opacos de ilmenita/magnetita, nódulos pedomórficos e litomórficos intrusivos, alterorrelíquia e pedorrelíquia de agregado (Figura 3B). A alterorrelíquia é composta por fragmento de basalto, em processo de alteração (Figura $3 \mathrm{C}$ ), sendo possível visualizar ripas de feldspatos alterando-se (STOOPS, 
2003). Os poros são constituídos predominantemente de planares, e secundariamente de câmaras, cavitários e canais, podendo ser observados poros com preenchimento incompleto denso, e ainda a presença de sutis hiporevestimentos de depleção. Verifica-se que o horizonte foi formado por materiais provenientes do arenito e do basalto, com predomínio do primeiro. O material é predominantemente apédico, com a presença de poucos poros cavitários e canais, sugerindo sutil transformação pedogenética pós-deposicional.

O horizonte $4 \mathrm{Cb}$ tem distribuição relativa predominante porfírica fechada, com grãos de quartzo, grãos opacos de ilmenita/magnetita, alteromorfo (Delvigne, 1998), alterorrelíquia de basalto e geodo (Figura 3D). Em relação aos poros verificam-se diferentes tipos (planares, vesiculares, cavitário, canais e compostos Quadro 2) sendo comuns preenchimentos soltos descontínuos. Registra-se hiporevestimento de depleção de poro e de grão. Os diferentes tipos de poros associados aos hiporevestimentos de depleção indicam que o material passou por variações no regime hídrico, possivelmente de úmido, com ação biogênica, a seco (STOOPS e SCHAEFER, 2010). Igualmente ao nível anterior, percebe-se se tratar de mistura de material proveniente tanto do intemperismo do basalto quanto do arenito. Alteromorfo, alterorrelíquias de basalto e geodo, minerais comuns em derrames vulcânicos, sugerem que a mistura se deu de materiais fontes com diferentes estágios de evolução pedogenética, possivelmente horizontes pedológicos B, BC e C (PAISANI e PONTELLI, 2012).

A análise realizada na transição entre os horizontes $5 \mathrm{Ab}$ e o $5 \mathrm{ACb}$, mostrou que a distribuição relativa predominante é porfírica fechada. São observados grãos de quartzo, ilmenita/magnetita, nódulos típicos pedomórficos e litomórficos intrusivos, litorrelíquias (fragmentos de basalto) e pedorrelíquias de agregado. $O$ material apresenta sutis laminações que podem decorrem da deposição por fluxo com baixo grau de viscosidade (Figura 3E) (BERTRAND e TEXIER, 1999). Em relação aos poros verifica-se a presença de diferentes tipos, planares, vesiculares, cavitários, canais e câmaras (Figura 3E), com destaque ao planares, os quais podem retratar fase de umectação/dessecação (STOOPS e SCHAEFER, 2010). Destaca-se a presença de hiporevestimentos de depleção e de impregnação, ambos de poro e de grão, e ainda revestimentos de crescimento, indicando iluviação (Figura 3F). É predominantemente apédico e localmente pédico, indicando que houve pouca 
transformação pedogenética. Isso se deve justamente ao fato de ser material em transição entre um horizonte A e AC.

Em geral, a análise micromorfológica dos horizontes $2 \mathrm{Ab}, 3 \mathrm{Cb}, 4 \mathrm{Cb}$ e na transição entre o $5 \mathrm{Ab}$ e o $5 \mathrm{ACb}$, corrobora a interpretação de origem coluvial para os materiais das unidades pedoestratigráficas. Além disso mostra que os materiais fonte das unidades estratigráficas 3, 4 e 5 são predominantemente derivados da pedogênese do arenito da Formação Botucatu, com sutis misturas de litorrelíquias provenientes do basalto da Formação Serra Geral.

Nos níveis 2, 3 e 4 a ausência de laminações remete a formação por fluxos viscosos, ou por sutis movimentos gravitacionais, ao passo que o nível 5 as laminações sugerem fluxo com baixa viscosidade, possivelmente vinculado ao escoamento superficial. A transição entre os horizontes $5 \mathrm{Ab}$ e $05 \mathrm{ACb}$ também expressa baixa pedogênese, vinculada a moderada bioturbação e principalmente a melanização. No caso deste nível pedológico se destacam microfeições que apontam para eventos de umectação e dessecação. Tais características contrastam com os horizontes do nível 6, subjacentes, marcados por forte hidromorfia. Desse modo, a transição entre o horizonte $5 \mathrm{Ab}$ e $5 \mathrm{ACb}$ reflete importante mudança paleoambiental relacionada ao regime hidrológico, que variou de úmido para sazonal afetando os horizontes superficiais (5Ab e $5 \mathrm{ACb})$ do hollow da paleocabeceira de drenagem.

Geocronologia dos registros estratigráficos e correlação com a cronologia do Quaternário Tardio

A datação por meio do ${ }^{14} \mathrm{C}$ foi realizada na fração húmica do horizonte $5 \mathrm{Ab} e$ revelou idade convencional de $28.770 \pm 1.200$ anos AP e calibrada de $33.004 \pm 702$ anos cal AP (Tabela 1). A idade calibrada sugere que o estabelecimento desse paleossolo se deu durante no Pleistoceno Superior e tem cronocorrelação com o Último Interestadial, equivalente ao Estágio Isotópico Marinho 3 (EIM 3). Igualmente, o nível pedoestratigráfico $4 \mathrm{Cb}$ também se estabeleceu durante o Pleistoceno Superior a cerca de $26.650 \pm 3.700$ anos AP (Tabela 1), porém na transição entre o final do Último Interestadial (EIM 3) e o início do Último Máximo Glacial, equivalente ao EIM 2. Para o nível 3Cb obteve-se idade de 22.000 \pm 3.200 anos AP (Tabela 1), posicionando-o no Pleistoceno Superior, cronocorrelato com o Último Máximo Glacial (EIM2). Já em relação ao nível pedoestratigráfico $2 \mathrm{ACb}$, a datação revelou 
idade de 2.100 \pm 380 anos AP, o que corresponde ao Holoceno Superior próximo do seu limite com o Holoceno Médio. O Holoceno equivale ao atual Interglacial (EIM1). Essas idades revelaram que o registro pedoestratigráfico corresponde ao Quaternário Tardio e apresenta um hiato cronológico entre o Último Máximo Glacial e o Holoceno Médio de aproximadamente 20.000 anos. Hiatos como esse foram registrados em seções pedoestratigráficas (códigos Hs2, Hs13, Hs16 e Hs17) na superfície de cimeira de Palmas/Caçador com intervalos de tempo de 13.540 a 19.830 anos AP que também se estenderam do Último Máximo Glacial até o Holoceno Médio (LOPES-PAISANI et al., 2016; PAISANI et al., 2019b). Situação similar foi encontrada em paleofundo de vale contido na Superfície de Cimeira de Vacaria (RS) (Pereira, 2017), sugerindo predomínio de fase erosiva de cunho regional nesse período.

Tabela 1 - Idades obtidas através do ${ }^{14} \mathrm{C}$ e Luminescência Opticamente Estimulada (LOE) dos horizontes $5 \mathrm{Ab}, 4 \mathrm{Cb}, 3 \mathrm{Cb}$ e $2 \mathrm{ACb}$

\begin{tabular}{|c|c|c|c|c|c|c|c|c|c|c|}
\hline \multicolumn{11}{|c|}{${ }^{14} \mathrm{C}$} \\
\hline $\begin{array}{l}\text { Horizo- } \\
\text { nte }\end{array}$ & \multicolumn{3}{|c|}{ Profundidade (cm) } & Cód. Lab. & \multicolumn{3}{|c|}{$\begin{array}{c}\text { Idade } \\
\text { convencional } \\
\text { (anos AP) }\end{array}$} & \multicolumn{2}{|c|}{$\begin{array}{l}\text { Idade calibrada } \\
\text { (anos AP) }\end{array}$} & $\begin{array}{l}\delta 13 C \\
(\% .)\end{array}$ \\
\hline $5 \mathrm{Ab}$ & \multicolumn{3}{|c|}{$205-215$} & $\begin{array}{c}\text { Beta- } \\
463356\end{array}$ & & \multicolumn{2}{|c|}{$28.770 \pm 1.200$} & \multicolumn{2}{|c|}{$33.004 \pm 702$} & $-16,1$ \\
\hline \multicolumn{11}{|c|}{ Luminescência Opticamente Estimulada } \\
\hline $\begin{array}{c}\text { Horizo } \\
\text { nte }\end{array}$ & $\begin{array}{l}\text { Prof. } \\
\text { (cm) }\end{array}$ & $\begin{array}{l}\text { Cód. } \\
\text { Lab. }\end{array}$ & $\begin{array}{c}\text { Th } \\
(\mathrm{ppm})\end{array}$ & $\underset{(p p m)}{U}$ & $\underset{(p p m}{K}$ & $\begin{array}{c}\text { Umi- } \\
\text { dade } \\
\text { (\%) }\end{array}$ & & $\begin{array}{l}\text { se } \\
\text { ual } \\
\text { ano-1) }\end{array}$ & $\begin{array}{c}\text { Paleo- } \\
\text { dose } \\
\text { Média } \\
\text { (Gy) }\end{array}$ & $\begin{array}{l}\text { Idade } \\
\text { (anos) }\end{array}$ \\
\hline $2 \mathrm{ACb}$ & $85-90$ & 4870 & $\begin{array}{c}6,184 \pm \\
0,342\end{array}$ & $\begin{array}{c}2,057 \pm \\
0,165\end{array}$ & $\begin{array}{r}0,396 \\
0,307 \\
\end{array}$ & 16,9 & 1.3 & \pm 225 & 2,9 & $\begin{array}{c}2.100 \pm \\
380\end{array}$ \\
\hline $4 \mathrm{Cb}$ & $\begin{array}{l}195- \\
200\end{array}$ & 572 & $\begin{array}{c}5,246 \pm \\
0,189\end{array}$ & $\begin{array}{c}2,216 \pm \\
0,219\end{array}$ & $\begin{array}{r}0,548 \\
0,079\end{array}$ & 8,6 & 1.7 & \pm 150 & 44,4 & $\begin{array}{l}26.650 \pm \\
3.700\end{array}$ \\
\hline $3 \mathrm{Cb}$ & $\begin{array}{l}150- \\
155\end{array}$ & 4573 & $\begin{array}{l}5,460 \pm \\
0,1975\end{array}$ & $\begin{array}{c}2,111 \pm \\
0,260\end{array}$ & $\begin{array}{r}0,508 \\
0,074\end{array}$ & $9,1 \pm$ & 1.6 & $0 \pm 160$ & 35,9 & $\begin{array}{l}22.000 \pm \\
3.200\end{array}$ \\
\hline
\end{tabular}

Análise Isotópica do Carbono

$\mathrm{Na}$ análise isotópica do carbono foram obtidos valores percentuais referentes ao carbono total e ao $\delta^{13} \mathrm{C}$ (Figura 4). A concentração de Carbono Total varia entre $3,49 \%$ no horizonte $2 \mathrm{ACb}$ (profundidade $90-100 \mathrm{~cm}$ ) e $1,37 \%$ na base do horizonte $3 \mathrm{Cb}$ (profundidade 160-170cm). Os valores mais elevados se encontram próximos à superfície, no topo do horizonte $2 A b(60-70 \mathrm{~cm})$ e no $2 \mathrm{ACb}(90-100 \mathrm{~cm})$. Com o aumento da profundidade, em direção à base do horizonte $3 \mathrm{Cb}(160-170 \mathrm{~cm})$, os valores decrescem, chegando ao menor valor registrado. A partir desse horizonte os valores aumentam, apresentando pouca variação. 
Em relação ao $\delta^{13} \mathrm{C}$, os valores variam entre $-21,91 \%$, topo do horizonte $2 \mathrm{Ab}$ $(60-70 \mathrm{~cm})$, a $-16,19 \%$ no horizonte $5 \mathrm{Ab}(205-215 \mathrm{~cm})$ (Figura 4). Valores mais negativos denotam predomínio de plantas com padrão fotossintético $C_{3}$ (Boutton, 1996; Pessenda et al., 1996; 2005), indicando predomínio de vegetação arbórea. Entre o horizonte $2 \mathrm{ACb}(90-100 \mathrm{~cm})$ e o topo do horizonte $3 \mathrm{Cb}(130-140 \mathrm{~cm})$ os valores apresentaram pouca variação, permanecendo em torno de $-16 \%$, sugerindo uma vegetação aberta do tipo $\mathrm{C}_{4}$ composta por gramíneas (Boutton, 1996; Pessenda et al., 1996; 2005), possivelmente um Campo Cerrado (MAACK, 1948; 1949). Com aumento da profundidade, entre a base do horizonte $3 \mathrm{Cb}(160-170 \mathrm{~cm})$ e o horizonte $4 \mathrm{Cb}(190-200 \mathrm{~cm})$, os valores são mais negativos, em torno de $-18 \%$. Tais valores indicam uma vegetação com presença de $\mathrm{C}_{3}$ e $\mathrm{C}_{4}$, porém com predomínio de plantas com ciclo fotossintético $\mathrm{C}_{4}$, apontando para uma vegetação em que predominam arbustos, gramíneas e alguns componentes arbóreos, talvez um Campo Cerrado (MAACK, 1948; 1949). Enfim, no horizonte 5Ab $(210-220 \mathrm{~cm})$, o valor menos negativo de $-16,1 \%$, indica predomínio de vegetação do tipo $C_{4}$, com a presença de gramíneas. Nesse último caso, o epipedon do hollow da cabeceira de drenagem se encontrava sobre horizontes hidromórficos, o que leva a pensar que 0 sinal isotópico era de vegetação composta por gramíneas mesofíticas devido à proximidade com o lençol freático (PAISANI et al., 2019b). O mesmo não se pode dizer para o sinal isotópico entre os horizontes $2 \mathrm{ACb}$ e $3 \mathrm{Cb}$, cujos registros estratigráficos estão distantes dos níveis hidromórficos, sugerindo que a vegetação era composta por gramíneas xerófitas. 
Figura 4 - $\delta 13 C$, carbono total e geocronologia dos principais níveis pedoestratigráficos.

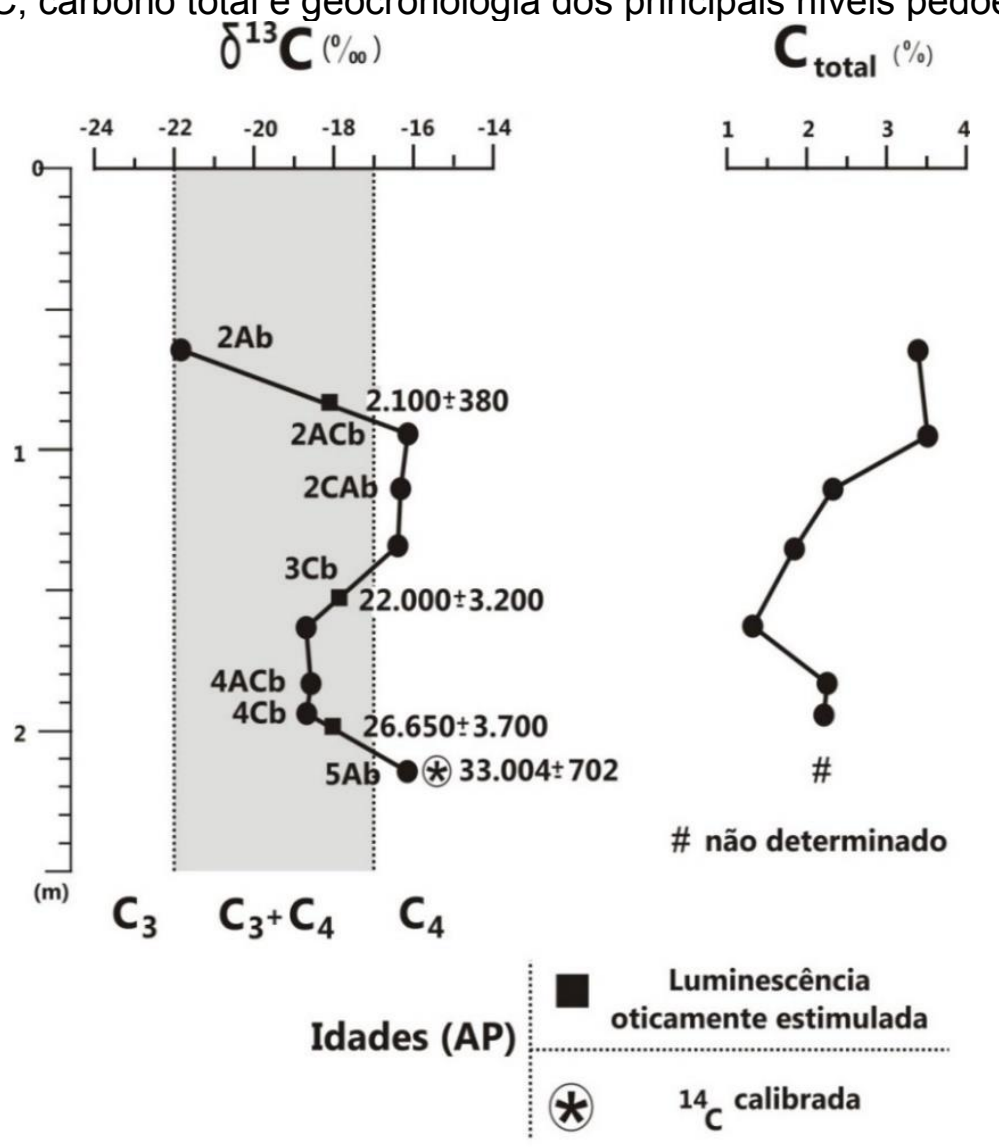

Sequência evolutiva e correlações paleoambientais

A partir das interpretações do registro estratigráfico e suas análises laboratoriais, pode-se apresentar modelo conceitual evolutivo para a paleocabeceira de drenagem estudada e estabelecer correlações com eventos paleoambientais regionais e globais. Em relação à arquitetura da seção estratigráfica verificou-se que a paleocabeceira de drenagem apresenta morfologia predominante suavemente côncava (média a alta encosta) e o topo convexo, consistindo atualmente em uma rampa de colúvios (PAISANI et al., 2016).

Inicialmente, o hollow da paleocabeceira de drenagem desenvolveu perfil de intemperismo de material in situ em condições hidromórficas (horizontes $6 \mathrm{Cg} 1 \mathrm{~b}$ a $6 \mathrm{Cg} 3 \mathrm{~b})$, atestando longo período de umidade com conexão hidrológica a rede de drenagem de baixa ordem, de forma perene. Nessa fase o hollow e as encostas circundantes estavam em equilíbrio dinâmico, com predomínio da pedogênese progressiva, conforme conceituação de Johnson et al. (1990) (Figura 4B). Epipedon rico em matéria orgânica se formou nas encostas e era sutilmente erodido e acumulado no hollow da paleocabeceira por conta da ação do escoamento superficial (horizonte $5 \mathrm{Ab}$ ). Nesse período, a vegetação predominante no hollow era 
de plantas $C_{4}$, possivelmente gramíneas mesofíticas (Paisani et al., 2019b), enquanto nas encostas circundantes havia mistura de plantas $\mathrm{C}_{3}$ com $\mathrm{C}_{4}$ (Figura 4B), constituída de vegetação relativamente aberta com predomínio de gramíneas. Não se pôde precisar esse momento, mas considerando-se a idade do horizonte 5Ab estima-se que foi anterior a 33.004 anos AP (Figura 4A).

Tal período de estabilidade ambiental, com predomínio de pedogênese progressiva, também foi detectado na Superfície de Cimeira de Palmas/Água Doce (PR-SC) e em paleofundo de vale contido na Superfície de Cimeira de Vacaria (RS) (PEREIRA, 2017; PAISANI et al., 2019b). Nessas superfícies foi registrada morfodinâmica ajustada a condições ambientais decorrente de clima relativamente úmido (Pereira, 2017; Paisani et al., 2019b), o que estaria em fase com os registros do core de Cambará do Sul (RS), referência do cenário paleoclimático das superfícies de cimeira do Planalto Vulcânico da Bacia do Paraná (BEHLING et al., 2004) (Figura 4C). Trata-se de um período cronocorrelato global ao Último Interestadial e/ou Estágio Isotópico Marinho 3, em que as áreas planálticas do sul do Brasil registraram aumento de temperaturas e umidade durante o Último Glacial (BEHLING et al., 2004; CRUZ JUNIOR et al., 2006).

Uma transição entre pedogênese progressiva e regressiva foi detectada no registro estratigráfico entre $33.004 \mathrm{a}>22.000$ anos $\mathrm{AP}$, considerando-se as idades dos níveis 5, 4 e 3 (Figura 4A,B). Nesse intervalo de tempo o epipedon 5Ab registrou mudanças em sua porosidade em escala microscópica, de cavitária para planar, foi truncado pela erosão, inclusive com desenvolvimento de erosão linear, e soterrado por fluxos viscosos que originaram o nível 4 . Sobre o nível 4 se desenvolveu epipedon que por sua vez passou pela mesma sequência de fenômenos de geogênese e pedogênese que o nível 5. Em conjunto, duas gerações de epipedon, horizontes $5 \mathrm{Ab}$ e $4 \mathrm{ACb}$, foram geradas, erodidas e soterradas no intervalo de 11.000 anos (Figura 4B). Esse evento coincide com pedocomplexos registrados na Superfície de Cimeira de Palmas/Caçador entre $>23.690$ a $~ 28.000$ anos AP (Paisani et al., 2014; 2019b), e constitui a resposta das paisagens em bacias de baixa ordem hierárquica $\left(<4^{\mathrm{a}}\right.$ ordem na classificação de Strahler, 1957) a transição de um regime hidrológico úmido para seco, onde passou a predominar a pedogênese regressiva em escala regional nas superfícies de cimeira do Planalto Vulcânico da Bacia do Paraná (PAISANI et al., 2019b). 
Figura 5 - Síntese dos principais fatos paleoambientais envolvidos na evolução da paleocabeceira de drenagem. Idades pelos métodos de ${ }^{14} \mathrm{C}$ e LOE (A). Pedogênese, taxa de erosão, erosão linear, taxa de sedimentação e padrão de fotossíntese da paleovegetação

(B). Inferências paleoclimáticas para área de estudo e as superfícies de cimeira de Palmas/Caçador e Cambará do Sul (C) (Modificado de Paisani et al., 2019b).

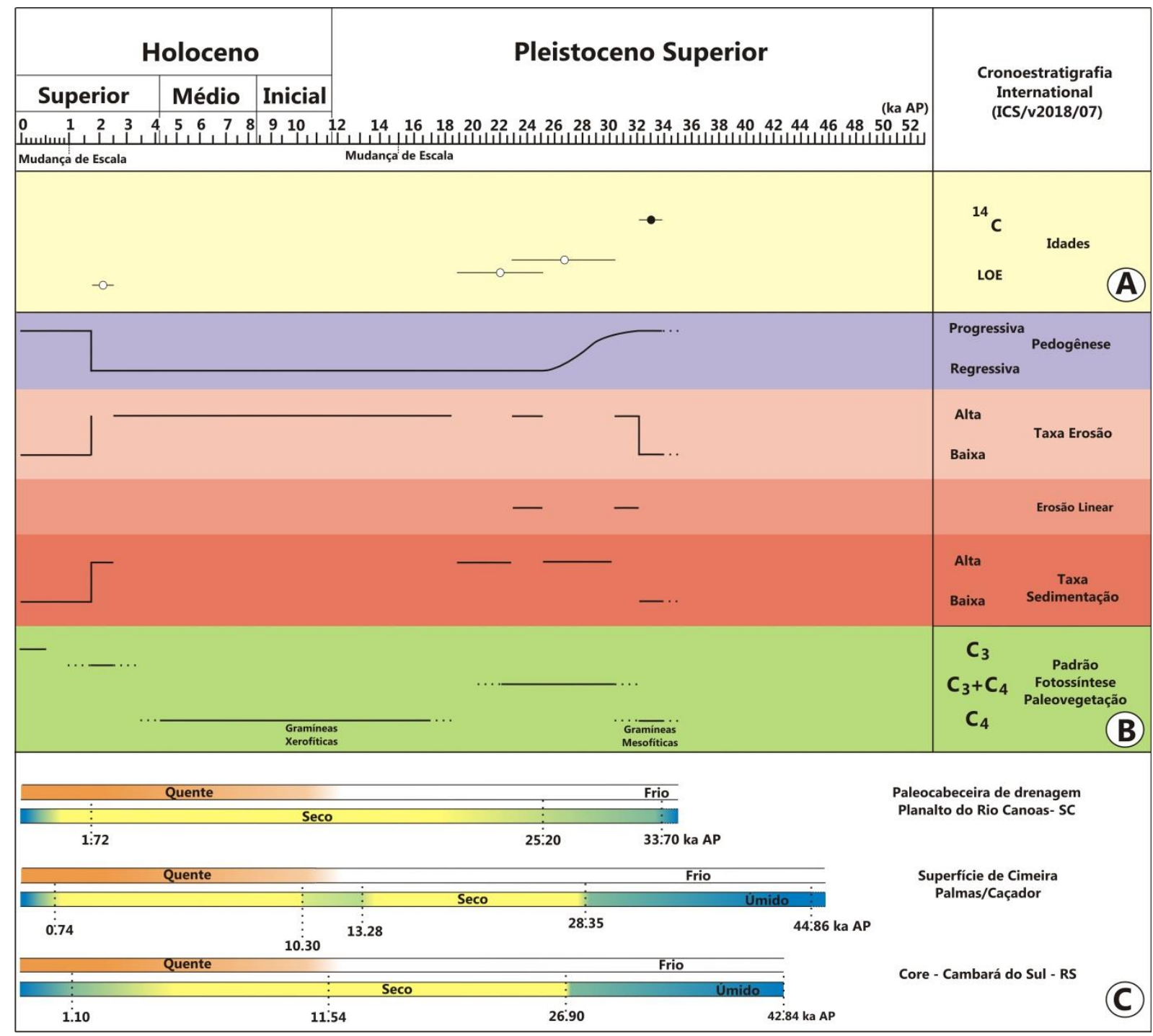

Entre $<26.650$ a $>2.100$ anos AP registra-se período seco com estabelecimento de vegetação $\mathrm{C}_{4}$ no hollow da paleocabeceira de drenagem, possivelmente constituída de gramíneas xerófitas. Nesse período a erosão predominou de forma sutil, não sendo suficiente para truncar totalmente o nível 4 . Flutuação rápida para mais úmido pode ter ocorrido, pois a 22.000 anos AP se estabeleceu o horizonte $3 \mathrm{Cb}$, cujo material parental caracteriza-se por colúvio gerado por fluxo viscoso. A análise micromorfológica corrobora para essa interpretação, ao registrar sucessão de poros cavitários com hiporevestimentos, indicativo de umidade, para poros planares, associados a dessecação. Tais resultados estão em fase com a plenitude da pedogênese regressiva $(>2.600 \mathrm{a}$ 
23.690 anos AP) registrada para a Superfície de Cimeira de Palmas-Caçador, cuja ocasião os fundos de vales de baixa ordem foram preenchidos sob regime climático seco com flutuações para úmido (PAISANI et al., 2019b). Nessa fase a paleocabeceira de drenagem da área de estudo inicia sua mudança morfológica para rampa de colúvio.

O Holoceno Superior foi marcado pela mudança de vegetação de uma mistura de plantas $\mathrm{C}_{3}$ com $\mathrm{C}_{4}$ para $\mathrm{C}_{4}$ (Figura $4,5 \mathrm{~B}$ ), reestabelecimento da pedogênese progressiva com desenvolvimento de epipedon e consequente redução das taxas de erosão e sedimentação (Figura 5B). Pela forte melanização do nível pedoestratigráfico 2, percebe-se que as condições climáticas se tornaram relativamente úmidas e frias (Figura $5 \mathrm{C}$ ), em fase com as condições ambientais registradas para as superfícies de cimeira vizinhas durante esse período (Figura $5 C)$.

\section{Conclusões}

Os registros estratigráficos da paleocabeceira de drenagem, balizados pela geocronologia, mostraram mudanças na pedogênese de progressiva para regressiva e vice-versa. Até 33.000 anos AP a paleocabeceira de drenagem esteve ativa, concentrando fluxos hipodérmicos em seu hollow e alimentando drenagem de baixa ordem perene sob regime climático úmido, coincidente com as condições paleoclimáticas do Último Interestadial (EIM 3). Entre 33.000 e >22.000 anos AP, a paleocabeceira de drenagem passou por sucessivos eventos de desenvolvimento de epipedon e truncamento pela erosão com estabelecimento de incisões lineares sob regime climático seco. A cerca de $<26.650$ até $>2.100$ anos AP o período seco se mantém, com erosão predominante, porém de forma sutil, com flutuação rápida para mais úmido, a cerca de 22.000 anos. Nessa fase a paleocabeceira de drenagem da área de estudo passou a iniciar sua mudança morfológica para rampa de colúvio. $\mathrm{O}$ Holoceno Superior foi marcado pelo reestabelecimento da pedogênese com desenvolvimento de epipedon e consequente redução das taxas de erosão e sedimentação. Percebeu-se mudanças na morfodinâmica da paleocabeceira de drenagem do Último Interestadial para o Holoceno Superior em fase com a dinâmica das bacias de baixa ordem em escala regional. 


\section{REFERÊNCIAS}

ASF DAAC. 2015. ALOS PALSAR Radiometric Terrain Corrected high resolution. 2019. Includes Material ( ) JAXA/METI 2007. (Acessado pelo ASF DAAC) 10 Nov., 2019. DOI: 10.5067/Z97HFCNKR6VA].

ALVARES, C.A.; STAPE, L.; SENTELHAS, P.C.; GONÇALVES, J.L.M.; SPAROVEK, G., 2014. Köppen's climate classification map for Brazil. Meteorol. Z. 22, 711-728. DOI: 10.1127/0941-2948/2013/0507.

BEHLING, H.; PILLAR, V.D.; ORLÓCI, L.; BAUERMANN, S.G., 2004. Late Quaternary Araucaria forest, grassland (Campos), fire and climate dynamics, studied by high-resolution pollen, charcoal and multivariate analysis of the Cambará do Sul core in southern Brazil.

Palaeogeografia, Palaeoclimatolologia e Palaeoecologia 203, 277-297.

DOI:10.1016/S0031-0182(03)00687-4.

BENDER, M. M. 1971. Variations in the $13 \mathrm{C} / 12 \mathrm{C}$ ratios of plants in relation to the pathway of photosynthetic carbon dioxide fixation. Phytochemistry 10(6), 1239-1244.

DOI:10.1016/s0031-9422(00)84324-1

BERTRAND, P.; TEXIER, J.P. 1999. Fabric characteristics of subaerial slope deposits. Catena 35 (2-4), 99-121. DOI: 10.1016/S0341-8162(98)00096-4

BIFFI, V. H. R. 2019. Evolução de encosta em contexto de paleocabeceira de drenagem da bacia do Rio Capão Grande no Quaternário Tardio - Superfície de

Pinhão/Guarapuava. Dissertação (Mestrado em Geografia - Unioeste/ Campus Francisco Beltrão).

BIRKELAND, P.W. 1999. Soils and Geomorphology. Oxford University Press, New York, 430 p. DOI:10.1002/esp.242

BOUTTON, T.W. 1996. Stable carbon isotope ratios of soil organic matter and their use as indicators of vegetation and climate change. In: Boutton, T.W.; Yamasaki, S.I. (Ed.) Mass spectrometry of soils. New York: Marcel Dekker, 47-82.

CALEGARI, M.R. 2008. Ocorrência e Significado Paleoambiental do Horizonte A Húmico em Latossolos (Tese de Doutorado). Escola Superior de Agricultura "Luiz de Queiroz" e ESALQ/USP.

CAMARGO FILHO, M. Aspectos Fundamentais da Evolução Geomorfológica Cenozoica da Bacia do rio Bananas- Guarapuava - PR. 1997. Dissertação (Mestrado em Geografia), UFSC.

CAMARGO FILHO, M.; BERTOTTI. L.G. ; SILVA, D. W. da ; GUERREIRO JUNIOR, L. A. 2016. Caracterização e distribuição de paleossolo de 44ka e sedimentos sobrepostos da encosta monjolo - Lapa-PR. Revista Geosul 31, 289-308. DOI: 10.5007/2177$5230.2016 \mathrm{v} 31 \mathrm{n} 61 \mathrm{p} 289$

CRUZ JÚNIOR, F. W.; BURNS, S. J.; KARMANN, I.; SHARP, W. D.;VUILLE, M. 2006. Reconstruction of regional atmospheric circulation features during the late Pleistocene in subtropical Brazil from oxygen isotope composition of speleothems. Earth and Planetary Science Letters, 248(1-2), 495-507. DOI:10.1016/j.epsl.2006.06.019 
DEINES, P. 1980. The isotopic composition of reduced organic carbon. In: Fritz, P., Fontes, J.C. (Eds.), Handbook of Environmental Isotope Geochemistry. Gisewir, Amsterdam.

DELVIGNE, J.E. 1998. Atlas of micromorphology of mineral alteration and weathering. Canadá: The canadian mineralogist, special publication 3, 495p.

DUTTA, K. 2016. Sun, Ocean, Nuclear Bombs, and Fossil Fuels: Radiocarbon Variations and Implications for High-Resolution Dating. Annual Review of Earth and Planetary Sciences 44:1, 239-275. DOI: 10.1146/annurev-earth-060115-012333

GHIBAUDO, G., 1992. Subaqueous sediment gravity flow deposits: practical criteria for their field description and classification. Sedimentology 39, 423-454. DOI: 10.1111/j.13653091.1992.tb02126.x

HUGHES, P.D. 2010. Geomorphology and Quaternary stratigraphy: role of morpho-, litho-, and allostratigraphy. Geomorphology 123, 189-199. 2010. DOI: 10.1016/j.geomorph.2010.07.025

INMET - Instituto Nacional de Meteorologia. 2019. Banco de Dados Meteorológicos para Ensino e Pesquisa - BDMEP. Brasília, DF, Brasil. Disponível em: http://www.inmet.gov.br/portal/index.php?r=bdmep/bdmep. Acesso em: 10 de Outubro de 2019.

JACQUES, P.D.; SALVADOR, E.D.; MACHADO, R.; GROHMANN, C.H.; NUMMER, A.R. 2014. Application of morphometry in neotectonic studies at the eastern edge of the Paraná Basin, Santa Catarina State, Brazil. Geomorphology 213, 13-23. DOI: 10.1016/j.geomorph.2013.12.037

JACQUES, P.D.; MACHADO, R.; NUMMER, A.R. 2015. Análise estrutural da Formação Serra Geral na porção Centro-Sul do estado de Santa Catarina, Brasil. Geociências (UNESP), 34 (3),390-401.

JOHNSON, D. L.; KELLER, E. A.;ROCKWELL, T. K. 1990. Dynamic pedogenesis: New views on some key soil concepts, and a model for interpreting Quaternary soils. Quaternary Research 33, 306-319. DOI: 10.1016/0033-5894(90)90058-S

KRUMBEIN, W.C. 1934. Size frequency distribution of sediments. Journal of Sedimentology and Petrology, 4 (2), 65-77. DOI: 10.1306/D4268EB9-2B26-11D78648000102C1865D

LOPES-PAISANI, S.D.L.; PAISANI, J.C.; OSTERRIETH, M.L.; PONTELLI, M.E.2016. Significado paleoambiental de fitólitos em registro pedoestratigráfico de paleocabeceira de drenagem - superfície de Palmas-Água Doce (Sul do Brasil). Geociências (UNESP) 35 (3), 426-442.

LUZ, L.D. ; PAROLIN, M.; PESSENDA, L.C.R.; RASBOLD, G.G.; EDWARD, L. 2019. Multiproxy analysis (phytoliths, stable isotopes, and $\mathrm{c} / \mathrm{n}$ ) as indicators of paleoenvironmental changes in a Cerrado site, southern Brazil. Revista Brasileira de Paleontologia/A Journal of the Brazilian Society of Paleontology, 22(1),15-29. DOI:10.4072/rbp.2019.1.02.

MAACK, R. 1948. Notas preliminares sobre clima, solos e vegetação do Estado do Paraná. Curitiba, Arquivos de Biologia e Tecnologia II, 102-200.

MAACK R. 1949. Notas complementares à apresentação preliminar do mapa fitogeográfico do Estado do Paraná (Brasil). Arquivos do Museu Paranaense 7, 351-361. 
MELO, M. S.; MEDEIROS, C. V. ; GIANNINI, P. C. F. ; GARCIA, M. J. ; PESSENDA, L. C. R. 2003a. Sedimentação quaternária no espaço urbano de Ponta Grossa, PR. Geociências (UNESP) 22 (1), 33-42.

MELO, M.S.; GIANNINI, P.C.F.; PESSENDA, L.C.R., BRANDT, N.M. 2003b. Holocene paleoclimatic reconstruction based on the Lagoa Dourada deposits, Southern Brazil. Geologica Acta 3, 289-302. DOI:10.1344/105.000001616

MORO, R.S.; BICUDO, C.E.M.; MELO, S.M.; SCHMITT, J. 2004. Paleoclimate of the Late Pleistocene and Holocene at Lagoa Dourada, Paraná State, Southern Brazil. Quaternary International, 114:87-99. DOI:10.1016/S1040-6182(03)00044-2

NEWMAN, J. W.; PARKER, P.L; BEHRENS, E.W. 1973. Organic carbon isotopic ratios in Quaternary cores from the Gulf of Mexico. Geochimica et Cosmochimica Acta 37, 225238.DOI: 10.1016/0016-7037(73)90130-0

NUMMER, A.R.; MACHADO, R.; JACQUES, P.D. 2014. Tectônica transcorrente mesozoica/cenozoica na porção leste do Planalto do Rio Grande do Sul, Brasil. Pesquisas em Geociências 41 (2), 121-130. DOI: 10.22456/1807-9806.78078

OLIVEIRA, M.A.T.; BEHLING, H.; PESSENDA, L.C.R. 2008. Late-Pleistocene and midHolocene environmental changes in highland valley head areas of Santa Catarina state, Southern Brazil. Journal of South American Earth Sciences, v. 26, p. 55-67. DOI:10.1016/j.jsames.2008.03.001.

OLIVEIRA, M.A.T. 1996. Evolução de voçorocas e integração de canais em áreas de cabeceira de drenagem: modelo conceitual, taxas de erosão e sinergia de mecanismos. Revista Geosul 19/20,153-182.

PAISANI, J. C. 2004. Utilização de diagrafias granulométricas no estabelecimento da lito e pedoestratigrafia de rampa arenosa costeira - o caso Praia Mole (Ilha de Santa Catarina). Geografia 13 (2), 138-151. DOI: 10.5433/2447-1747.2004v13n2p139

PAISANI, J. C.; PONTELLI, M. E. 2012. Propriedades micromorfológicas de colúvios em encosta no médio vale do Rio Marrecas (Sudoeste do Estado do Paraná) - bases para distinção de formações superficiais alóctones e autóctones em substrato basáltico.

Pesquisas em Geociências 39 (1), 53-62. DOI: 10.22456/1807-9806.35814

PAISANI, J.C.; PONTELLI, M.E.; CORRÊA, A.C.B.; RODRIGUES, R.A.R., 2013.

Pedogeochemistry and micromorphology of oxisols - a basis for understanding etchplanation in the Araucárias Plateau (Southern Brazil) in the Late Quaternary. Journal of South American Earth Sciences 48, 1-12. DOI: 10.1016/j.jsames.2013.07.011.

PAISANI, J.C.; PONTELLI, M.E.; OSTERRIETH, M.L.; PAISANI, S.D.L.; FACHIN, A.; GUERRA, S.; OLIVEIRA, L., 2014. Paleosols in low-order streams and valley heads in the Araucaria Plateau - record of continental environmental conditions in Southern Brazil at the end of MIS 3. Journal of South American Earth Sciences 54, 57-70. DOI: 10.1016/j.jsames.2014.04.005.

PAISANI, J.C.; FACHIN, A.; PONTELLI, M.E.; OSTERRIETH, M.L.; LOPES-PAISANI, S.D.L.; FUJITA, R.H. 2016. Evolução de paleocabeceira de drenagem do rio Chopinzinho (Sul do Brasil) durante o Quaternário Superior. Revista Brasileira de Geomorfologia, v. 17, p. 43-59. DOI: 10.20502/rbg.v17i1.735. 
PAISANI, J.C.; LOPES-PAISANI, S.D.; LIMA, S.; RIBEIRO, F.J.; PONTELLI, M.E.; FUJITA, R.H. 2019a. Paleoenvironmental dynamics of low-order paleovalleys in the Late Quaternary - Palmas/Caçador Summit Surface - Southern Brazil. Catena 182, 104171. DOI:10.1016/j.catena.2019.104171

PAISANI, J.C.; SANTOS, L.J.C.; GOUDARD, G.; GOULART, A.A.; BIFFI, V.H.R. 2019b. Subtropical Araucárias Plateau. In: Salgado, A.A., Santos, L.J.C., Paisani, J.C. (Eds.), Physical geography of Brazil, Springer, Switzerland AG, pp.in press. DOI: 10.1007/978-3030-04333-9_3

PELOGGIA, A. U. G. 1998. O homem e o ambiente geológico: geologia, sociedade e ocupação urbana no município de São Paulo. São Paulo: Xamã.

PAGOTTO, D., 2018. Pedogênese e morfogênese em cabeceira de drenagem no Planalto de Canoas (SC) no Quaternário tardio. Dissertação de Mestrado. Universidade Estadual do Oeste do Paraná.

PASSOS, J. R. ; CAMARGO FILHO, M. . Identificação de Linha de Pedra em Guarapuava PR.Terr@ Plural (UEPG. Online), v. 9, p. 102-118, 2015.

PELUSO JUNIOR, V. A. 1986. O Relevo do Território Catarinense. Revista Geosul, 2(1), 769.

PEREIRA, J.M. 2017. Pedogênese e morfogênese na Superfície de São José dos Ausentes (RS) no Quaternário Tardio: evidências em paleofundo de vale de segunda ordem hierárquica. Dissertação (Mestrado em Geografia) - Universidade Estadual do Oeste do Paraná, Francisco Beltrão - PR.

PESSENDA, L.C.R.; ARAVENA, R.; MELFI, A.J.; TELLES, E.C.C.; BOULET, R.; VALENCIA, E.P.E.; TOMAZELLO, M. 1996. The use of carbono isotopes $\left({ }^{13} \mathrm{C},{ }^{14} \mathrm{C}\right)$ in soil to evaluate vegetation changes during the Holocene in Central Brazil. Radiocarbon. 38, 191-201. DOI: $10.1017 / \mathrm{S} 0033822200017562$

PESSENDA, L. C. R.; GOUVEIA, S. E. M.; FREITAS, H. A. D.; RIBEIRO, A. D. S.; ARAVENA, R.; BENDASSOLLI, J. A.; LEDRU, M-P.; SIEFEDDINE, A. F.; SCHEELYBERT, R. 2005. Isótopos do carbono e suas aplicações em estudos paleoambientais. In: SOUZA, C. R. D. G.; SUGUIO, K.; OLIVEIRA, A. M. D. S.; OLIVEIRA, P. E. D (Org). Quaternário do Brasil. Ribeirão Preto: Editora Holos, 75-93.

RHODES, E.J. 2011. Optically stimulated luminescence dating of sediments over the past 200,000 years. Annual Review of Earth and Planetary Sciences 39, 461-488. DOI: 10.1146/annurev-earth-040610-133425

SANTA CATARINA. 1986. Atlas de Santa Catarina. Gabinete de Planejamento e Coordenação Geral. Subchefia de Estatística, Geografia e Informática, 1 atlas. Escalas Variadas.

SANTOS, R. D. D; LEMOS, R. C. D; SANTOS, H. G. D; KER, J. C.; ANJOS, L. H. C. D. 2005. Manual de descrição e coleta de solo no campo. Viçosa: Sociedade Brasileira de Ciência do Solo, 92 p.

SCHAETZL, R. J.; ANDERSON, S. 2005. Soils: Genesis and Geomorphology. Cambridge: University Press, 833p. 
SORDI, M.V.; SALGADO, A.A.R.; PAISANI, J.C. 2015. Evolução do relevo em áreas de tríplice divisor de águas regional - o caso do Planalto de Santa Catarina: análise morfoestrutural. Revista Brasileira de Geomorfologia, 16 (4), 579-592. DOI: 10.20502/rbg.v16i4.791

SORDI, M.V.; SALGADO, A.A.R.; PAISANI, J.C. 2016. Compartimentação geomorfológica em áreas de tríplice divisor de águas regional - o caso do planalto de Santa Catarina. Geociências (UNESP) 35 (4), 623-64.

SORDI, M.V.; SALGADO, A.A.R.; PAISANI, J.C.; PAGOTTO, D. 2017. Controle litoestrutural no desenvolvimento de vales na área do rebordo da Bacia do Paraná no Estado de Santa Catarina, Sul do Brasil. Revista Brasileira de Geomorfologia 18(4), 671-687. DOI: 10.20502/rbg.v18i4.1189.

SORDI, M. V.; SALGADO, A. A. R.; SIAME, L.; BOURLÉS, D. ; PAISANI, J. C.; LEANNI, L.; BRAUCHER, R. ; COUTO, E. V.; ASTER TEAM. 2018. Implications of drainage rearrangement for passive margin escarpment evolution in southern Brazil. Geomorphology 306, 55 - 169. DOI: 10.1016/j.geomorph.2018.01.007

STOOPS, G. 2003. Guidelines for analysis and description of soil and regolith thin sections. Soil science society of America, Inc. USA.

STOOPS, G.; SCHAEFER, C.E.G.R. 2010. Pedoplasmation: formation of soil material. In: Stoops G, Marcelino V, Mees F. (EDS). Interpretation of micromorphological features of soils and regoliths. Amsterdam: Elsevier, 69-79.

STRAHLER, A. N. 1957. Quantitative analysis of watershed geomorphology. Eos Trans. AGU 38(6), 913-920. DOI: 10.1029/TR038i006p00913.

TARDY, Y. 1993. Pétrologie des latérites et des sols tropicaux. Paris, Masson, 459p.

\section{NOTAS DE AUTOR}

\section{CONTRIBUIÇÃO DE AUTORIA}

Dayane Pagotto - Concepção. Coleta de dados, Análise de dados, Elaboração do manuscrito Julio Cesar Paisani - Concepção e elaboração do manuscrito. Coleta de dados Participação ativa da discussão dos resultados; Revisão e aprovação da versão final do trabalho.

Michael Vinicius de Sordi: Elaboração do manuscrito, revisão e aprovação da versão final do trabalho.

\section{FINANCIAMENTO}

A presente pesquisa foi parcialmente financiada pelos projetos CNPQ (Conselho Nacional de Desenvolvimento Científico e Tecnológico) (Projetos 441501/2014-1, 441647/2014-6 e 300902/2015-8) e CAPES-COFECUB 869/15. A primeira e terceiro autores receberam bolsas de estudo de mestrado e doutorado, respectivamente.

\section{CONSENTIMENTO DE USO DE IMAGEM}

Não se aplica.

APROVAÇÃO DE COMITÊ DE ÉTICA EM PESQUISA

Não se aplica. 


\section{LICENÇA DE USO}

Este artigo está licenciado sob a Licença Creative Commons CC-BY-NC. Com essa licença você pode compartilhar, adaptar, criar para qualquer fim, sem uso comercial e desde que atribua a autoria da obra.

\section{HISTÓRICO}

Recebido em: 19-12-2019

Aprovado em: 16-04-2020 